Journal of the Electrochemical Society, 1991, Vol. 138, No. 8, pp. 2253-2259.

ISSN: (Print 0013-4651) (Online 1945-7111)

http://www.electrochem.org/

http://scitation.aip.org/JES

http://scitation.aip.org/getpdf/servlet/GetPDFServlet?filetype=pdf\&id=JESOAN000138000008002253000001 \&idty pe $=$ cvips\&prog $=$ normal

(C) The Electrochemical Society, Inc. 1991. All rights reserved. Except as provided under U.S. copyright law, this work may not be reproduced, resold, distributed, or modified without the express permission of The Electrochemical Society (ECS). The archival version of this work was published in Journal of the Electrochemical Society, Vol. 138, No. 8, 1991, pp. 2253-2259.

\title{
Copper Corrosion With and Without Inhibitors
}

\author{
V. Brusic, M. A. Frisch, B. N. Eldridge, F. P. Novak, F. B. Kaufman, B. M. Rush, and G. S. \\ Frankel \\ IBM Research Division, T.J. Watson Research Center, Yorktown Heights, New York.
}

\begin{abstract}
The utility of copper interconnects may ultimately depend on the ability to protect copper from corrosion. We have studied the capacity of $1 H$-benzotriazole $(1 H$-BTA) to provide a protective and stable surface film able to withstand harsh chemical and thermal environments. The film was characterized with electrochemical techniques, in situ ellipsometry, ex situ time-of-flight static secondary ion mass spectrometry, high-temperature mass spectrometry, and accelerated temperature and humidity tests. Several important passivating film properties (thickness, degree of polymerization, thermal stability, corrosion resistance) depend critically on the details of the film preparation conditions. The best corrosion protection is offered by the thin film formed on an oxidized $\mathrm{Cu}$ surface. This film has also shown the slowest growth kinetics and the highest degree of polymerization in the $\mathrm{Cu}-\mathrm{BTA}$ structure.
\end{abstract}

With more aggressive performance requirements for multilevel interconnections, higher conductivity metals, such as copper, are finding their way into a number of products. Copper is a relatively noble metal. Nevertheless, it reacts easily in ordinary, oxygen containing, environments (1). In view of the limited passivation offered by $\mathrm{Cu}$-oxides, we have studied the effectiveness of organic azoles, such as $1 H$-benzotriazole $(1 H$-BTA), as a general method of controlling $\mathrm{Cu}$ degradation. For over 40 years $1 H$-BTA has been successfully used in the prevention of atmospheric $\mathrm{Cu}$ corrosion (2), in packaging, storage and transport, in the reduction of thermal oxidation and, in particular, in the protection of copper under immersed conditions (Ref. (3) and references within). The relevant literature is abundant but not unified in its teaching about bonding, thickness, composition and structure of the resulting film and the nature of its protection.

Recent work from our laboratory, based on a combination of electrochemical, ellipsometric, and XPS data, has shown that the spontaneous reaction of $\mathrm{Cu}$ and $1 H$-BTA under a variety of conditions leads to the formation of $\mathrm{Cu}$-BTA $(4,5)$, with copper being $\mathrm{Cu}^{+1}$, as reported elsewhere (6-12). The formation of a $\mathrm{Cu}-\mathrm{N}$ bond was clearly identified from the $\mathrm{Cu}$ LMM Auger lines. The film was formed both on an oxidized and an oxide-free $\mathrm{Cu}$ surface, in contrast to reports suggesting that the presence of $\mathrm{Cu}_{2} \mathrm{O}$ is a prerequisite for the buildup of $\mathrm{Cu}$ BTA $(8,14)$. The thickness of the film was determined to be $0.5-4 \mathrm{~nm}$ in the $\mathrm{pH}$ range from 3 to 12 , reaching $25 \mathrm{~nm}$ only under harsh conditions, i.e., in $\mathrm{pH} 2$. Several recent studies of ultrahigh vacuum deposited $1 H$-BTA have indeed detected $1 H$-BTA adsorption on clean $\mathrm{Cu}$ metal (14-16). An electrochemical equivalent of such a film was formed in our laboratory at $\mathrm{Cu}^{0}$ kept in 
solution at a low cathodic potential; it reached a limiting thickness of about $0.5 \mathrm{~nm}$ or less (4), which could be the result of an adsorbed monolayer. Under oxidizing conditions, however, the growth of a three-dimensional Cu-BTA film was shown to proceed by a logarithmic or parabolic growth law (5). Thus, ionic movement through the film seems to be the rate-determining step, as similarly observed in metallic oxides. This indicates that the bulk of the growth is neither by a chemisorption [suggested in (13) and (17)], nor, strictly speaking, by a dissolution-precipitation mechanism [postulated in (6-12)]. The latter prevails only in very acidic conditions (5). In milder solutions, $\mathrm{pH} 4-12$, the film apparently always grows in a self-inhibiting manner, but there are differences in kinetics and film thickness depending on $\mathrm{pH}$ and the state of the copper surface prior to the contact with $1 H$-BTA. Thus, one could postulate that the structure of films formed on oxide-free and oxidized $\mathrm{Cu}$ are different.

The purpose of this work is to develop a broad fundamental understanding of the $\mathrm{Cu}$ BTA structure as a function of film preparation conditions. We also wish to evaluate the thermal stability of these films and define their effectiveness against corrosion in environments which do not contain a $1 H$-BTA reservoir.

\section{Experimental}

Samples and electrolytes.-Experimental work was conducted with sputtered $\mathrm{Cu}$ films, about $2 \mu \mathrm{m}$ thick, deposited over a thin adhesion layer on a $\mathrm{Si}$ wafer. Electrolytes used were distilled and deionized (DI) water, $0.1 N \mathrm{~K}_{2} \mathrm{SO}_{4},\left(\mathrm{NH}_{4}\right)_{2} \mathrm{~S}_{2} \mathrm{O}_{8}$, and $\mathrm{Fe}\left(\mathrm{NO}_{3}\right)_{3}$. Solutions of $\mathrm{K}_{2} \mathrm{SO}_{4}$ were chosen to provide environment with different $\mathrm{pH}$ values. The $\mathrm{pH}$ was adjusted with either $\mathrm{H}_{2} \mathrm{SO}_{4}$ or $\mathrm{KOH}$ and ranged from 2 to 13 . The other solutions, known as etchants for $\mathrm{Cu}$, were used to evaluate the effectiveness of the $1 H$-BTA under truly aggressive conditions which sometimes occur in $\mathrm{Cu}$ processing. All solutions were used with or without $1 H$-BTA. The $1 H$ BTA concentration in all cases was $0.01 M$.

Growth of $\mathrm{Cu}$-BTA.-Electrochemical techniques were used both to control and to study the state of the copper surface. They were combined with in situ applied ellipsometry having $1 \mathrm{~s}$ time resolution. The electrochemical cell was air-tight, made of Kel-F and equipped with quartz windows to allow passage of light. A Teflon needle was used to introduce $1 H$-BTA. In order to prepare an oxide-free surface, native oxides initially present on $\mathrm{Cu}$ were either reduced potentiostatically or dissolved spontaneously in some of the electrolytes. In either case, ellipsometry was used to optimize the process, i.e., to select conditions with minimal interference of $\mathrm{H}_{2}$ evolution (occurring with oxide reduction at cathodic potentials) or surface roughening (following oxide dissolution in aggressive electrolytes).

$1 H$-BTA was added to the working solution at the point in the experiment when the copper surface was properly pretreated:

1. In most of the experiments, $1 H$-BTA was introduced while the copper was in an oxide-free state (e.g., potentiostated at low potential), followed immediately by oxidation at open-circuit potential.

2. In some experiments, carried out in solutions with $\mathrm{pH} 8-12,1 H$-BTA was added after the native oxides were reduced and the electrode was subsequently reoxidized to $\mathrm{Cu}_{2} \mathrm{O}$.

3. In water and neutral solutions, studies were also conducted on $\mathrm{Cu}$ without electrode pretreatment, measuring the $\mathrm{Cu}$-BTA growth on native oxides. Such a process is of practical importance with possible application to products which cannot easily be subjected to 
electrochemical control or harsh chemicals.

Characterization of copper after exposure to $1 H$-BTA. - Cu-BTA films were further evaluated ex situ for thermal stability by high-temperature mass spectrometry, for surface structure by time-of-flight static secondary ion mass spectroscopy (ToF-SSIMS), and for corrosion resistance by electrochemical and temperature/humidity $(\mathrm{T} / \mathrm{H})$ tests.

High-temperature mass spectrometry.-The thermal stability of the BTA films on copper was studied by Knudsen effusion mass spectrometry (KEMS). This technique is a powerful method for studying decomposition reactions because the order and activation energy of the kinetic processes can be derived directly from the mass spectroscopic data (18). The instrumentation of the high-temperature mass spectrometer system is described in detail elsewhere (19). Several important features are incorporated in this system resulting in an exceptionally high sensitivity. These include a differentially pumped ultrahigh vacuum environment for both the mass spectrometer and furnace, the use of digital modulation techniques, and fully automated instrumentation.

Copper squares, $7 \times 7 \mathrm{~mm}$, with a deposited $\mathrm{Cu}$-BTA film were weighed in a platinum cup to better than $10 \mu \mathrm{m}$ precision. The samples were heated in an all-platinum Knudsen cell whose interior dimensions were $1.80 \mathrm{~cm}$ diam and $3.00 \mathrm{~cm}$ high, giving a volume of $2.75 \mathrm{~cm}^{3}$. The orifice, $1 \mathrm{~mm}$ diam by $5 \mathrm{~mm}$ long, was on the cylindrical surface of the cell. The conductance of this orifice for the typical gases evolved in these studies is less than $30 \mathrm{~cm}^{3} / \mathrm{s}$ which yields a time resolution of about $0.1 \mathrm{~s}$. The orifice can be accurately aligned with the entrance to the cross-beam ionizer of the quadrupole mass spectrometer. For temperature measurement and control, a Pt vs. 90\% Pt-10\%Rh thermocouple was welded to the surface of the cell near the sample position. The Knudsen cell was heated radiatively with a tungsten-mesh element from room temperature to the maximum temperature of $427^{\circ} \mathrm{C}$ using linear ramps of either 1 or $2^{\circ} \mathrm{C} / \mathrm{min}$. In those experiments which were run at $1^{\circ} \mathrm{C} / \mathrm{min}$, the initial ramp from room temperature to $227^{\circ} \mathrm{C}$ was made at $2^{\circ} \mathrm{C} / \mathrm{min}$ to reduce the overall time required. The molecular beam from the Knudsen cell was modulated and the time-dependent gas composition measured with an automated quadrupole mass spectrometer. The gases were ionized using $30 \mathrm{eV}$ electrons, which minimized the contributions of fragment ions to the ion intensity for the simpler species in the spectrum. After heating, the samples were reweighed and the weight losses, where significant, were correlated with the integrated ion signals from the mass spectrometer for pressure calibration.

In the exploratory phase of our study, the complete mass spectrum from $\mathrm{m} / \mathrm{z} 12$ to 211 was measured repetitively during the entire temperature program. Each ion was counted for 0.4 $\mathrm{s}$, which gave about a $3^{\circ} \mathrm{C}$ temperature resolution for the $27 \mathrm{~min}$ ramp. These wide-scan desorption spectra showed that $1 H$-BTA was the principal gas desorbing. Thus, in subsequent experiments, to increase our sensitivity in detecting the $1 H$-BTA species desorbing from the ultrathin films, we measured only the parent (and most abundant) ion ( $\mathrm{m} / \mathrm{z} 119)$. This ion was counted for $10 \mathrm{~s}$ repetitively, which yielded a temperature resolution of $0.2^{\circ} \mathrm{C}$ for the $1{ }^{\circ} \mathrm{C} / \mathrm{min}$ ramp.

To calibrate the ion signal at $\mathrm{m} / \mathrm{z} 119$, we vaporized about $1 \mathrm{mg}$ of pure $1 \mathrm{H}-\mathrm{BTA}$ at $2^{\circ} \mathrm{C} / \mathrm{min}$. This sample was fully desorbed by $100^{\circ} \mathrm{C}$. From the integration of the ion signal at $\mathrm{m} / \mathrm{z}$ 119 , our detection sensitivity for the $1 H$-BTA species is about $3 \times 10^{9}$ molecules desorbed for each ion detected. Since our background count at m/z 119 is only about 10 counts/min, we 
should be able to observe about 0.001 of a monolayer of 1H-BTA desorbing during the programmed heating.

Experimental data are normally recorded as the variation of the ion-signal intensity at $\mathrm{m} / \mathrm{z}$ 119-with the sample temperature and time. With the help of a computer program, data are $(i)$ replotted as a logarithm of the ion intensity vs. 1/T, and (ii) curve-fitted to obtain the parameters of the reaction kinetics, i.e., the reaction order, frequency factor, and the activation energy.

Time-of-flight static SIMS.-ToF-SSIMS is a powerful technique for analysis of the near surface $(\mathrm{d}<1 \mathrm{~nm})$ region of organic layers. Operation of the spectrometer in the static regime is accomplished by limiting the integrated ion dose delivered to the target to less than $10^{13}$ ions per $\mathrm{cm}^{2}$, or about $1 / 100$ of a monolayer of total exposure. In this way the effect of ion-beam induced damage on the mass spectra collected is minimized (20). In the course of this study, no effect of ion dose on the mass spectra collected was observed. The time-of-flight mass analyzer allows for simultaneous collection of all ions with $\mathrm{m} / \mathrm{z} 1$ to about 5000 Daltons. The upper limit is determined by the efficiency of the channel plate used for ion detection. Positive and negative ion spectra gathered from a wide range of materials have demonstrated that static SIMS spectra of organic molecules and polymer systems are characteristic of the structure of the materials under study (21). A complete description of the apparatus used for these experiments has been published elsewhere (22).

Corrosion tests $-\mathrm{Cu}$ samples with $\mathrm{Cu}-\mathrm{BTA}$ films were exposed to $80 \%$ relative humidity $(\mathrm{RH})$ at $80^{\circ} \mathrm{C}$ for 14 days and compared to copper without a BTA film on similar tests. As the main reactants in this case are expected to be water and oxygen, all of the samples were also tested electro-chemically in pure water. The tests in this case were carried out in a simple electrochemical cell that was originally developed for the evaluation of corrosion reactions in a droplet of an electrolyte with a high resistivity, such as distilled and deionized water, and is described elsewhere (23).

The rate of copper dissolution and its change with time after $1 H$-BTA addition were evaluated from polarization resistance measurements and, at steady state, from potentiodynamic polarization curves. Electrochemical potentials were measured and reported against a mercurous sulfate electrode (MSE).

\section{Results and Discussion}

Effect of $\mathrm{pH}$ and $1 \mathrm{H}$-BTA on copper corrosion.-The corrosion rate as a function of $\mathrm{pH}$ is given in Fig. 1, being the lowest in the $\mathrm{pH}$ range of 7-12, where $\mathrm{Cu}$-oxides are stable (1). In all cases, dissolution of $\mathrm{Cu}$ is balanced by the reduction of oxygen which is diffusion limited (Fig. 2). Addition of $1 \mathrm{H}$-BTA to an oxide-free $\mathrm{Cu}$ surface causes a drastic decrease in $\mathrm{Cu}$ dissolution at all $\mathrm{pH}$ values, even in the presence of etchants such as $\mathrm{Fe}\left(\mathrm{NO}_{3}\right)_{3}$ and $\left(\mathrm{NH}_{4}\right)_{2} \mathrm{~S}_{2} \mathrm{O}_{8}$ (Fig. 1 and 2). The effect of $1 H$-BTA is significantly enhanced corrosion protection over that provided by $\mathrm{Cu}$ oxides under optimal conditions, i.e., in alkaline solutions.

In solutions with $1 H$-BTA, a decrease of the $\mathrm{Cu}$ corrosion rate is coupled with an increase in the corrosion potential. These trends have been observed for all cases in this study, with the highest magnitude measured in water/l $H$-BTA solution for oxidized $\mathrm{Cu}$. The latter is shown as an example in Fig. 2. Such a variation of corrosion parameters indicates that the BTA film on the $\mathrm{Cu}$ surface acts primarily to retard the exodus of $\mathrm{Cu}$ ions and secondarily as a barrier for oxygen 
reduction.

Growth of Cu-BTA on copper.-The work with $\mathrm{Cu}$ in simple solutions, without $1 H$-BTA or etchants, provided us with useful background information on $\mathrm{Cu}$ surface chemistry. This, as well as some aspects of $\mathrm{Cu}$-BTA growth, are reported in detail elsewhere $(4,5)$. Some of our previously reported findings were utilized in the preparation of samples for the current task. These will be summarized here for completeness and clarity.

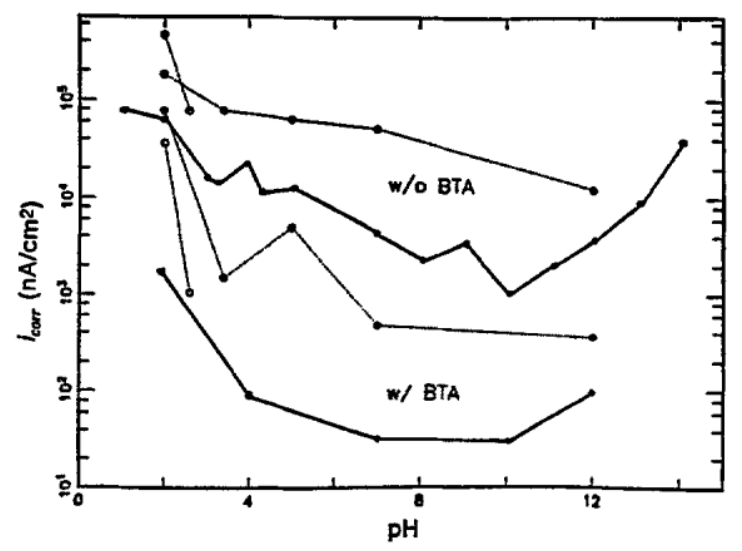

Fig. 1. Effect of $\mathrm{pH}$ and $1 \mathrm{H}-\mathrm{BTA}$ on the corrosion rate of $\mathrm{Cu}$ in $0.1 \mathrm{~N} \mathrm{~K}_{2} \mathrm{SO}_{4}$ adjusted to $1<\mathrm{pH}<14$ with $\mathrm{H}_{2} \mathrm{SO}_{4}$ or $\mathrm{KOH}$, solid line. Results in $\left(\mathrm{NH}_{4}\right)_{2} \mathrm{~S}_{2} \mathrm{O}_{8}$ are given with dashed line and data in $\mathrm{Fe}\left(\mathrm{NO}_{3}\right)_{3}$ with dashed line and open circles.

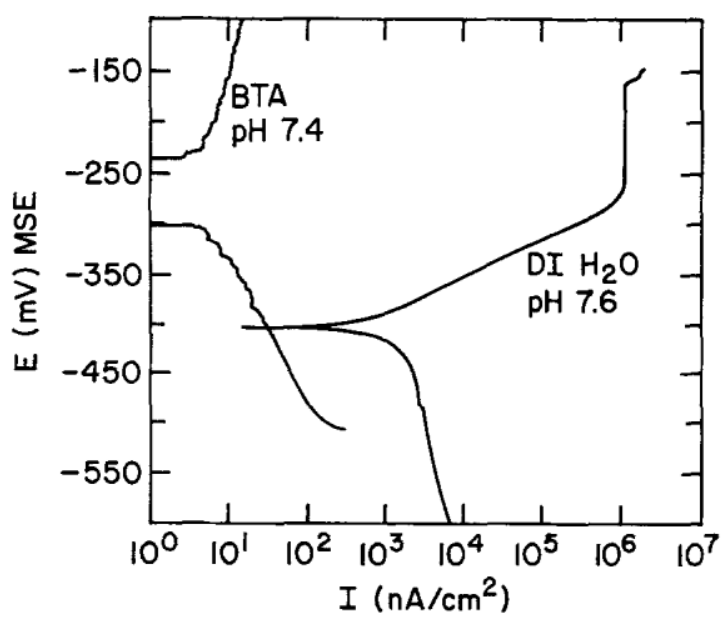

Fig. 2. Potentiodynamic polarization curves measured on $\mathrm{Cu}$ in a droplet of water and a droplet of water containing $0.01 \mathrm{M} 1 \mathrm{H}-\mathrm{BTA}$. $\mathrm{Cu}$ was used without any surface pretreatment.

In combination with electrochemical data, ellipsometric and XPS surface analyses show that in $\mathrm{pH}$ 8-12 stable oxides of $\mathrm{Cu}$ can be formed reversibly. At $\mathrm{pH} 7$, the process begins to be affected by dissolution of $\mathrm{Cu}$. At $\mathrm{pH} 2-5$, dissolution of $\mathrm{Cu}$ is rapid and the formation of stable surface oxides is not possible. Ellipsometric data, in support of these statements, are given in Fig. 3 and 4.

Figure 3 shows changes of ellipsometric parameters $\Delta$ and $\psi$ measured in $\mathrm{N}_{2}$-saturated 
$\mathrm{KOH}$, as the copper electrode undergoes potentiostatic reduction of native oxides, reoxidation at a potential close to the corrosion potential (repeated twice), and the formation of Cu-BTA (upon injection of $1 H$-BTA into the solution). The change in $\mathrm{A}$ is proportional to the thickness of a surface film and depends on the optical-properties of the bare metal and the film. The index of refraction of the bare copper was uniquely determined from the ellipsometric values, measured at low cathodic potential $(-1.6 \mathrm{~V})$. Indexes of the oxide and $\mathrm{Cu}$-BTA films were obtained from the best fit of experimental and theoretical variation of $d \Delta / d \psi$ slopes. For the oxide, the apparent ${ }_{f}^{*}=2.6-0.1 \mathrm{~K}$, while for the $\mathrm{Cu}-\mathrm{BTA}$ the $\mathrm{n}_{\mathrm{f}},=1.8$ on an oxidized surface and $n_{f}^{*}=1.8-0.05 \mathrm{~K}$ when the film is grown from an oxide-free surface. In this case, a $1^{\circ}$ change in $\Delta$ corresponds approximately to a change in oxide thickness of $0.55 \mathrm{~nm}$ and to a variation of $\mathrm{Cu}$-BTA thickness of about $1 \mathrm{~nm}$. Thus the data in Fig. 3, given in terms of the experimental $\mathrm{d} \Delta$ values (measured in degrees and presented as a difference from the values obtained on oxide-free $\mathrm{Cu}$ ), can be simply translated into film thickness. The results show that at the open-circuit potential (region I), native oxides are stable. Once a low cathodic potential is applied (region II) this $2.5 \mathrm{~nm}$ thick film is rapidly reduced. An increase of potential to $-0.45 \mathrm{~V}$ (close to the corrosion potential at this $\mathrm{pH}$ ) leads to rapid growth of $\mathrm{Cu}_{2} \mathrm{O}$ (region III), which can be reduced (region IV) and reproducibly reformed (region $\mathrm{V}$ ), reaching a thickness of about $1.4 \mathrm{~nm}$. The fact that the optical properties return to the values for oxide-free copper upon reduction at $-1.6 \mathrm{~V}$ is an indication that surface roughening does not interfere with these measurements. Reaction of $\mathrm{Cu}$ with $1 \mathrm{H}$-BTA is clearly detectable (region VI). The uptake of $1 H$-BTA, similar to the oxide growth, is initially rapid, and then slowing down into a logarithmic change with time, forming a film about $1.7 \mathrm{~nm}$ thick in 10 min. In contrast to the oxide, the $\mathrm{Cu}$-BTA film is not fully reducible (region VII).
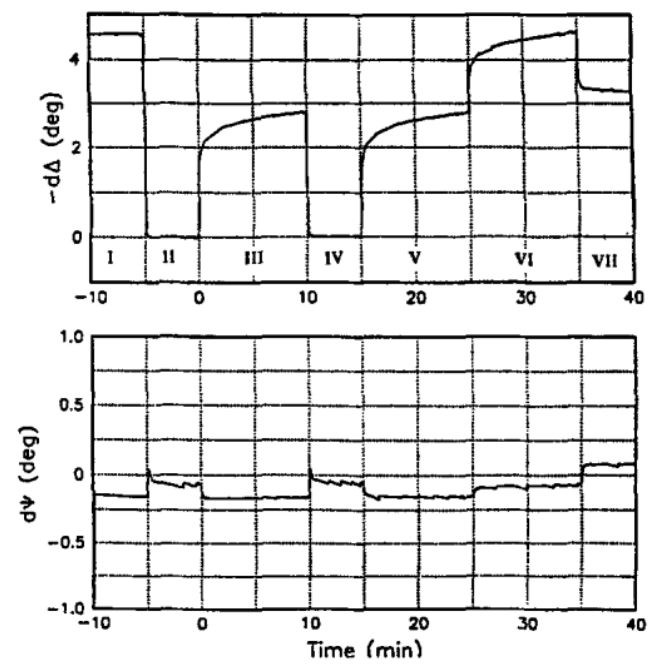

Fig. 3. Variation of ellipsometric parameters $\Delta$ and $\psi$ with $\mathrm{Cu}$ surface reduction, reoxidation, and growth of $\mathrm{Cu}$ BTA, in $\mathrm{pH} 12$. 

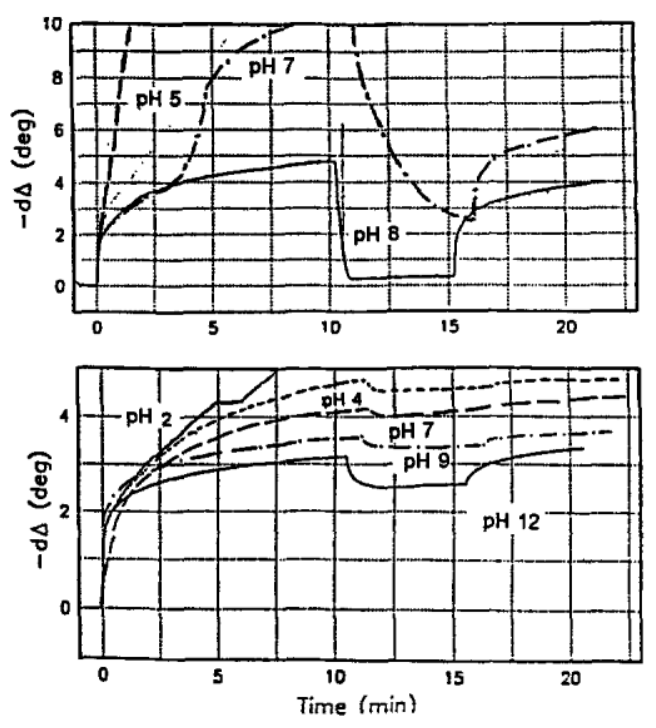

Fig. 4. Variation of $\mathrm{d} \Delta$ with spontaneous reoxidation of oxide-free $\mathrm{Cu}$ in solutions without $1 H$-BTA (upper graph) and with $1 H$-BTA (lower graph). Zero time corresponds to a release of the potentiostatic control at low potential, followed by oxidation at open-circuit potential.

At $\mathrm{pH}$ values below 7, native copper oxides are easily removed, either by cathodic reduction or by spontaneous dissolution. Ellipsometry measures optical parameters corresponding to the oxide-free state. XPS data confirm this finding. Samples exposed for $30 \mathrm{~s}$ to a $\mathrm{pH} 4$ solution and introduced into the XPS chamber without exposure to air, show no oxide on the surface (4). At the corrosion potential such a surface is not stable, resulting in large irreversible changes of A due to dissolution and surface roughening (Fig. 4). In contrast, with addition of $1 H$-BTA (starting from the bare surface), $\mathrm{Cu}$ oxidation at the corrosion potential leads to the formation of a well-behaved film throughout the $\mathrm{pH}$ range from 12 to 4 (Fig. 4). At $\mathrm{pH} 2$ the ellipsometric data are irregular, irreproducible, and difficult to fit to a reasonable growth equation (Fig. 4). One can suspect that the results are in error due to surface roughening. This cannot be easily proved or disproved, however, since the $\mathrm{Cu}$-BTA film in all cases shows an irreversible presence. Assuming that the elipsometric data are not erroneous and are indeed representative of the $\mathrm{Cu}-\mathrm{BTA}$ film, the data indicate that the film thickness increases as $\mathrm{pH}$ decreases. This trend is fully confirmed by $x$-ray photo-electron spectroscopy (XPS) evaluation of film thicknesses on similar samples (4), as well as by calibration and integration of ion signals in high-temperature mass spectrometry (see below). The film growth can be best represented by a logarithmic law at high $\mathrm{pH}$ values changing to a parabolic law at neutral and mildly acidic $\mathrm{pH}$ and finally to a dissolution-precipitation mechanism at $\mathrm{pH} 2$. Examples of the growth kinetics at pH 12 and 4 are given in Fig. 5.

$\mathrm{Cu}$-BTA growth kinetics and overall film thickness also depend on whether the $\mathrm{Cu}$ surface was oxide-covered or not prior to $1 H$-BTA addition. In neutral electrolytes as stated above, the growth of $\mathrm{Cu}$-BTA on the oxide-free surface is parabolic with time, leading to a film 3.5-4 nm thick in $10 \mathrm{~min}$. In contrast, the $\mathrm{Cu}$-BTA thickness on $\mathrm{Cu}$ oxide varies logarithmically with time, reaching about $2 \mathrm{~nm}$ after $10 \mathrm{~min}$ of immersion (Fig. 6), and $2.3 \mathrm{~nm}$ in $30 \mathrm{~min}$. It is apparent from Fig. 6. that the logarithmic growth on an oxidized $\mathrm{Cu}$ surface is established seconds after contact with $1 H$-BTA when the Cu-BTA thickness, on average, is $1.2 \mathrm{~nm}$, i.e., greater than a monolayer. One could speculate that the early film growth is a consequence of $1 H$-BTA 
adsorption at sites with different adsorption energies. However, the data in this work indicate that even the thinnest film, formed in less than a second, is a new compound, which contains oxidized $\mathrm{Cu}$-ion (see below, $\mathrm{Cu}$-BTA structure by ToF-SSIMS). Thus, the preferred postulate is that the film thickness behavior at shorter times is a consequence of patchy growth, a nuclei of monomolecular thickness spread laterally to cover the surface. The transition to either logarithmic or parabolic growth behavior is an indication that ionic movement through the film has become the rate-determining step. The onset of such kinetics indicates that the $\mathrm{Cu}-\mathrm{BTA}$ coverage has exceeded a monolayer at all points on the surface. Ion movement, described by a logarithmic law, is kinetically slower than ion diffusion, represented by a parabolic law. Thus, the $\mathrm{Cu}$-BTA film on oxidized $\mathrm{Cu}$ provides a better barrier to ionic travel than the film on an oxide-free surface. For this reason one can speculate that the films with different growth kinetics also have a different structure.
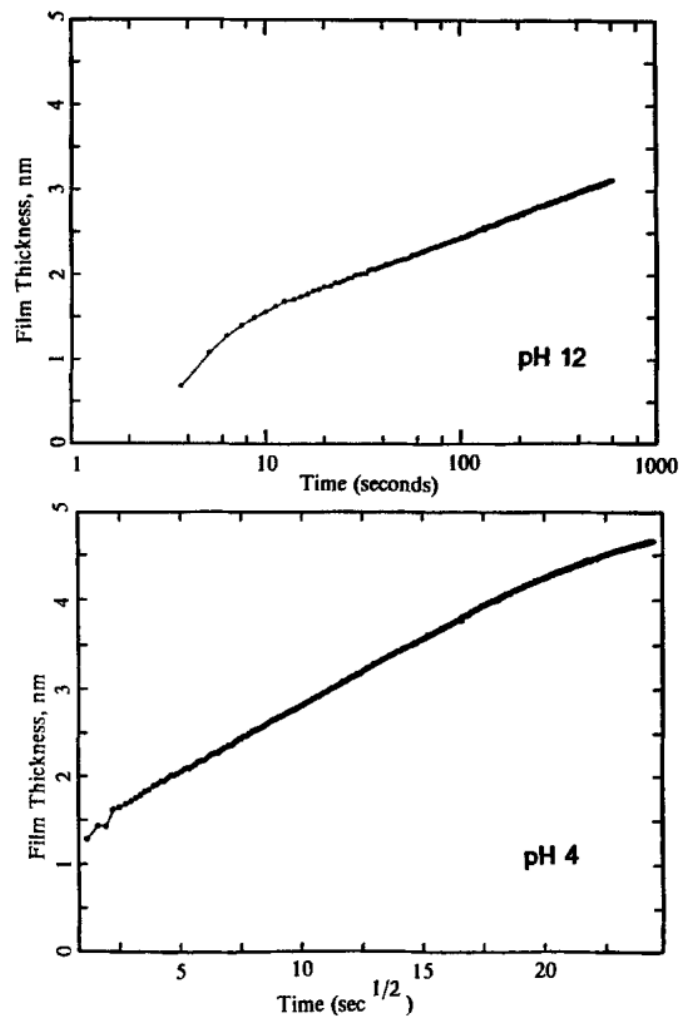

Fig. 5. Kinetics of Cu-BTA film formation in $\mathrm{pH} 12$ (upper graph) and $\mathrm{pH} 4$ (lower graph). 


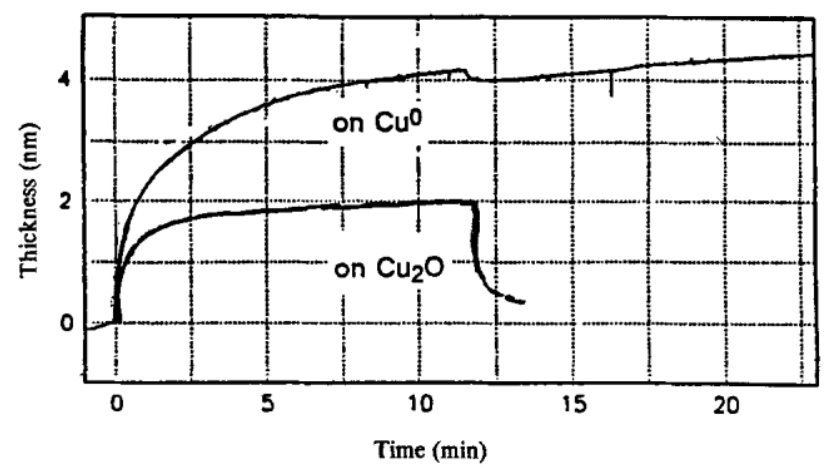

Fig. 6. Difference in $\mathrm{Cu}-\mathrm{BTA}$ film growth on oxidized and oxide-free $\mathrm{Cu}$ surface in $\mathrm{pH} 7$.

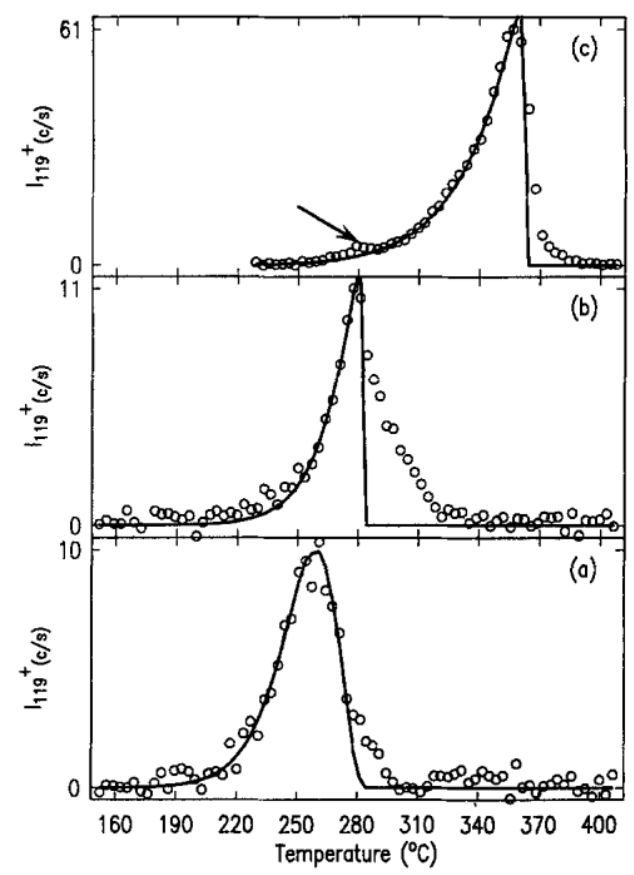

Fig. 7. Charge counts corresponding to $\mathrm{m} / \mathrm{z} 119$ as a function of temperature obtained by a programmed heating of the $\mathrm{Cu}$-BTA samples (a) prepared in water without oxide removal, (b) prepared in neutral solution on oxide-free $\mathrm{Cu}$, and (c) made in $\mathrm{pH} 2$ solution; the arrow is pointing to the prepeak in the spectra which grows with aging. The points are experimental data, while the solid line represents the computer-fitted curve used to evaluate the parameters of reaction kinetics.

Thermal stability of Cu-BTA films on copper.-The thermal stability of Cu-BTA is known to be good to about $250^{\circ} \mathrm{C}$ (7). Indeed, while pure $1 \mathrm{H}$-BTA evaporates readily at temperatures below $100^{\circ} \mathrm{C}$ (see Experimental), Cu-BTA films on similar tests show no thermal activity below about $200^{\circ} \mathrm{C}$ (Fig. 7). Decomposition of Cu-BTA films results in an ionic spectrum, in which the most abundant peak, by far, is the parent ion at m/z 119, $(1 H \text {-BTA })^{+}$. Since the $1 H$-BTA vapor is observed as the principal decomposition product, the reaction must have some source of hydrogen. The most likely one is the water included in the film during the preparation. The more complete mechanism is the subject of the further study and will be reported in the future. 
The results in Fig. 7 illustrate that the kinetics of $\mathrm{Cu}$-BTA degradation depend on the method of preparation and storage time. The figure shows the evolution of $1 H$-BTA as a function of temperature. The experimental data were utilized to model the reaction kinetics according to the following differential equation

$$
-d N / d t=N^{n} A e^{-\mathrm{E}_{a} / \mathrm{RT}}
$$

where $N$ is the number of unreacted molecules, $n$ is the reaction order, $A$ is the frequency factor, $E_{a}$ is the activation energy, $R$ is the gas law constant, and $T$ is the temperature in kelvin. In fitting the calculated curve to the data, the overall shape is determined by both the reaction order and activation energy, while the peak temperature is determined by the frequency factor. If only one reaction is occurring in the temperature regime, then the activation energy is best derived from the initial stage of the reaction. At this point, the activity of unreacted BTA species on the surface is close to unity and thus the rate is independent of the reaction order. The calculated rates of molecules effusing from the Knudsen cell, $-d N / d t$, were normalized to the mass spectrometric measurements using the integrated area under the curve.

This analytical treatment is shown in Fig. 7 for three of the studied films. The calculated curves (solid lines) overlay the experimental data (circles) with good precision. Films prepared on an oxide at $\mathrm{pH} 7$ dissociate most readily, with a peak temperature of $259^{\circ} \mathrm{C}$, first-order kinetics, a heat of activation of about $160 \mathrm{~kJ} / \mathrm{mol}$, and frequency factor of $1.0 \times 10^{13} / \mathrm{s}$ (curve a). Since copper oxides are not thermally stable, curve (a) could be an artifact resulting from the thermal dissociation of an underlying oxide. Films grown from the oxide-free surface at the same $\mathrm{pH}$ show a peak temperature of $281^{\circ} \mathrm{C}$, with a heat of activation close to $166 \mathrm{~kJ} / \mathrm{mol}$ and frequency factor of $1.0 \times 10^{13} / \mathrm{s}$ (curve b). This film was prepared at the $\mathrm{pH}$ where both $\mathrm{Cu}$-oxide and $\mathrm{Cu}-\mathrm{BTA}$ could grow on the surface; assignment of the activation energy is complicated possibly due to a coexistence of multiple bonds. The most stable films are those prepared at low $\mathrm{pH}$, i.e., $\mathrm{pH}$ 2, with a peak temperature of $359^{\circ} \mathrm{C}$, almost zero-order kinetics, a heat of activation of about $130 \mathrm{~kJ} / \mathrm{mol}$, and frequency factor of $1.0 \times 10^{7} / \mathrm{s}$ (curve c). Samples prepared in acidic $\mathrm{pH}$ and measured several days after the deposition show a growth of a prepeak at a lower temperature (see arrow, Fig. 7c), indicating possible structural changes. This will be discussed later.

Cu-BTA structure by ToF-SSIMS - Samples evaluated by ToF-SSIMS were prepared in a similar fashion as the samples for investigation of thermal stability, i.e., in $\mathrm{pH} 7$ with or without surface oxide reduction and in $\mathrm{pH}$ 2. The data obtained differ significantly from the results of a recent study where $1 \mathrm{H}$-BTA was adsorbed on sputtercleaned $\mathrm{Cu}$ under UHV conditions (16). Static SIMS analysis of UHV-prepared films formed in the absence of surface oxygen revealed no ions heavier than $\left(\mathrm{Cu}(\mathrm{BTA})_{2}\right)^{-}$or $\left(\mathrm{Cu}(\mathrm{H} H-\mathrm{BTA})_{2}\right)^{+}$, regardless of the final film thickness. In contrast, samples in this study have shown ions of the type $\left(\mathrm{Cu}_{n-1}(\mathrm{BTA})_{n}\right)^{-}$, type $\mathrm{A}$, and $\left.(\mathrm{Cu}-\mathrm{BTA})_{4}\right)^{+}$, type $\mathrm{B}$, with $x \geq 2$. These ions were produced in varying degrees of abundance depending on the sample preparation conditions. The heaviest ions observed correspond to $\left(\mathrm{Cu}_{5}(\mathrm{BTA})_{4}\right)^{+}$, with a principal peak at $\mathrm{m} / \mathrm{z} 787$ in the positive ion spectra. The negative ion spectrum in Fig. 8 was obtained from a $\mathrm{Cu}$-BTA film grown in water/l $\mathrm{H}$-BTA on an unreduced $\mathrm{Cu}$ surface. Clearly visible in the figure are species of type A with $n=2$ (with the mass of $\mathrm{m} / \mathrm{z} 388$ ) and $n=3$ (with the mass of $\mathrm{m} / \mathrm{z} 480$ ).

Our results also indicate that the relative intensities of the type $\mathrm{A}$ and $\mathrm{B}$ ions are a 
function of film thickness for layers prepared on oxidized $\mathrm{Cu}$ (Table I). It was further established that the relative intensities of these species show a pronounced dependence on the film preparation conditions (Table II). Table I summarizes the results in the form of the observed intensity of type A ions and other fragment ions relative to that of the $\mathrm{BTA}^{-}$parent ion at $\mathrm{m} / \mathrm{z}$ 118. Films of different thicknesses were prepared on oxidized copper by controlling the immersion time of the untreated copper in the $1 H$-BTA solution $(\mathrm{pH} 7.3)$. Negative ion spectra of very thin films prepared in this way, i.e., 0.1 and $0.4 \mathrm{~nm}$ thick, show the presence of BTA-Cu$\mathrm{BTA}^{-}$ions, but no ions above $\mathrm{m} / \mathrm{z} 299$. As the average thickness increases to $\geq 0.8 \mathrm{~nm}$, the relative intensity of $\mathrm{Cu}-\mathrm{BTA}-\mathrm{OH}^{-}$ion decreases while the signals corresponding to type A ions increase. This probably indicates that covering of the original oxidized surface is almost complete. Films with thicknesses $\geq 1.2 \mathrm{~nm}$ have similar SSIMS spectra to those shown for the 2.0 $\mathrm{nm}$ thick film, except that there is an increase in the abundance of high mass ions with increasing film thickness.

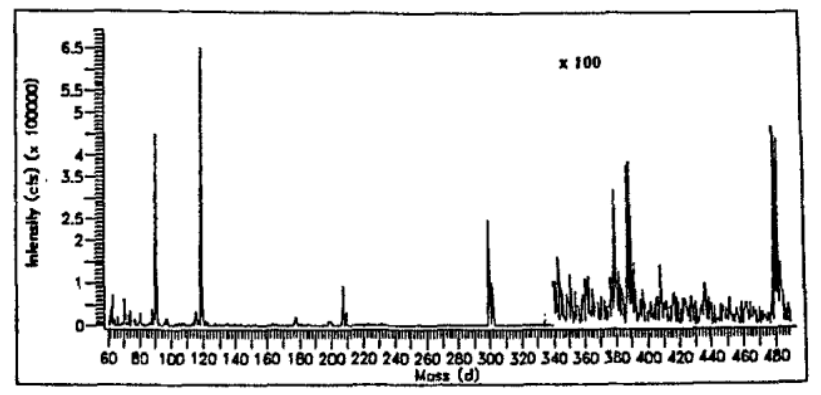

Fig. 8. A typical negative ion spectrum obtained in ToF-SSIMS on $2.0 \mathrm{~nm}$ thick $\mathrm{Cu}-\mathrm{BTA}$ film prepared in $\mathrm{pH} 7 \mathrm{on}$ oxidized $\mathrm{Cu}$.

Table I. Relative intensities of cracking fragments of $\mathrm{Cu}-\mathrm{BTA}$ formed on the oxidized $\mathrm{Cu}$ in $\mathrm{pH} 7$.

\begin{tabular}{lllcll}
\hline & & \multicolumn{4}{c}{ Cu-BTA thickness, $\mathrm{nm}$} \\
\cline { 3 - 6 } $\mathrm{m} / \mathrm{z}$ & \multirow{2}{*}{ Structure } & 0.1 & 0.4 & 0.8 & 2.0 \\
\hline 118 & (BTA)- $^{-}$ & 1 & 1 & 1 & 1 \\
198 & BTA-Cu-OH $^{-}$ & 0.043 & 0.050 & 0.015 & 0.016 \\
207 & BTA-Cu-CN $^{-}$ & 0.028 & 0.039 & 0.048 & 0.138 \\
299 & BTA-Cu-BTA- $^{-}$ & 0.054 & 0.083 & 0.217 & 0.361 \\
388 & BTA $_{2}$ Cu $_{2}$ CN $^{-}$ & - & - & 0.0012 & 0.0047 \\
480 & BTA $_{3} \mathrm{Cu}_{2}^{-}$ & - & - & 0.0022 & 0.0068
\end{tabular}

Spectra obtained from $\mathrm{Cu}$-BTA grown on oxide-free $\mathrm{Cu}(\mathrm{pH}$ 7) exhibit lower peak intensities at $\mathrm{m} / \mathrm{z} 299,388$, and 480 relative to those obtained from films grown on native oxides (Table II). Films formed at $\mathrm{pH} 2$ show an even weaker intensity at $\mathrm{m} / \mathrm{z} 299$ and no peaks at masses 388 and 480. This is exemplified in Table II by films obtained in $\mathrm{Fe}\left(\mathrm{NO}_{3}\right)_{3}$ and $\left(\mathrm{NH}_{4}\right)_{2} \mathrm{~S}_{2} \mathrm{O}_{8}$.

The observation of "chain-like" ions of types A and B is consistent with published results which suggest that $\mathrm{Cu}$-BTA forms a polymerized structure. Table II also shows that the observed intensity of higher mass species is clearly dependent on the film preparation method. This is further evidence that intensities of the type A ions are representative of surface structure and not simply a consequence of increased number density. The simplest interpretation of these results is that the higher intensities of these ions indicate a greater degree of $\mathrm{Cu}-\mathrm{BTA}$ polymerization. The building block for polymerization is assumed to be the bidentate structure proposed by Cotton 
(24), Poling (7), and Nilsson et al. (15) for coordination between $\mathrm{Cu}$ and BTA. The structure is the result of $\mathrm{Cu}$ being bonded to the amino-nitrogen, on one side, and attached to the electron pair on an unsaturated ring nitrogen, on another (24). A more complete discussion of the behavior of the SSIMS spectra, including the correlation between the ellipsometrically determined film thickness and the behavior of the main and secondary peaks of Fig. (8) is in preparation.

The slowest growing films, i.e., those grown at $\mathrm{pH} 7$ on native oxides, are the thinnest films and exhibit self-limiting growth. These films are also the most polymerized and as will be discussed below also provide the greatest corrosion protection. The fastest growing films, i.e.,

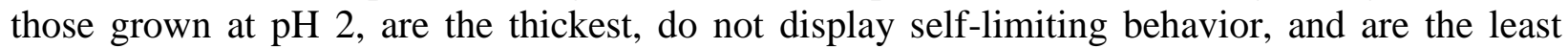
polymerized. These films offer the least corrosion protection. The effects of film aging, clearly evident in the thermal tests, were not detected by ToF-SSIMS. The latter technique only samples the near surface layer $(1 \mathrm{~nm})$, while the former samples the entire film. Thus, the observed aging effects are most likely the consequence of an internal oxidation process. Poling (7) reported that $\mathrm{Cu}-\mathrm{BTA}$ films formed in acidic solutions ( $\mathrm{pH} 3$ ), acted primarily as cathodic inhibitors of the hydrogen evolution reaction but not of the oxygen reduction reaction. The data of this work support this picture (see Fig. 9). This suggests that the film is permeable to oxygen. With time, $\mathrm{Cu}$ oxidation could then proceed at the $\mathrm{Cu} / \mathrm{Cu}-\mathrm{BTA}$ interface.

Table II. Relative intensities of cracking fragments of $\mathrm{Cu}$-BTA formed on 1 . Oxidized $\mathrm{Cu}$ in $\mathrm{pH} 7$, with an average thickness of $2.0 \mathrm{~nm}$; 2. oxide-free $\mathrm{Cu}$ in $\mathrm{pH} 7,7.0 \mathrm{~nm}$ thick; 3. oxide-free $\mathrm{Cu}$ in $\mathrm{pH} 2 \mathrm{Fe}\left(\mathrm{NO}_{3}\right)_{3}, 30 \mathrm{~nm}$ thick; and 4. oxide-free $\mathrm{Cu}$ in $\mathrm{pH} 2\left(\mathrm{NH}_{4}\right)_{2} \mathrm{~S}_{2} \mathrm{O}_{\mathrm{B}}, 5.0 \mathrm{~nm}$ thick.

\begin{tabular}{llllcc}
\hline & & \multicolumn{4}{c}{ Cu-BTA Film } \\
\cline { 3 - 6 } $\mathrm{m} / \mathrm{z}$ & \multirow{2}{*}{ Structure } & & \multicolumn{4}{c}{2} & 3 & 4 \\
\hline 118 & (BTA) $^{-}$ & 1 & 1 & 1 & 1 \\
198 & BTA-Cu-OH $^{-}$ & 0.016 & 0.011 & 0.007 & 0.040 \\
207 & BTA-Cu-CN $^{-}$ & 0.138 & 0.047 & 0.032 & 0.097 \\
299 & BTA-Cu-BTA $^{-}$ & 0.361 & 0.061 & 0.041 & 0.089 \\
388 & BTA $_{2} \mathrm{Cu}_{2} \mathrm{CNN}^{-}$ & 0.0047 & 0.001 & - & - \\
480 & BTA $_{3} \mathrm{Cu}_{2}^{-}$ & 0.0068 & 0.001 & - & -
\end{tabular}

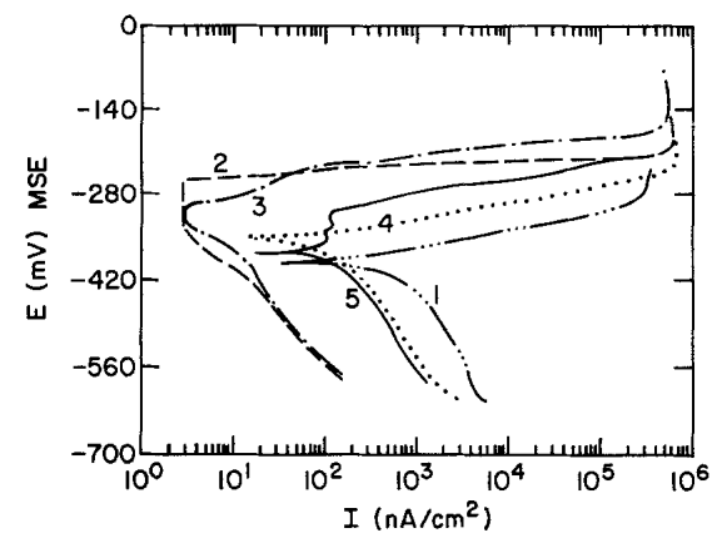

Fig. 9. Potentiodynamic polarization curves measured in a droplet distilled water on $\mathrm{Cu}$ (1) without pretreatment, (2) with $2.0 \mathrm{~nm}$ thick $\mathrm{Cu}$-BTA formed on oxidized $\mathrm{Cu}$ in $\mathrm{pH} 7$, (3) with $5.5 \mathrm{~nm}$ thick $\mathrm{Cu}-\mathrm{BTA}$ formed on oxide-free $\mathrm{Cu}$ in $\mathrm{pH} \mathrm{7,} \mathrm{(4)} \mathrm{with} 5.5 \mathrm{~nm}$ of $\mathrm{Cu}-\mathrm{BTA}$ formed in $\mathrm{Fe}\left(\mathrm{NO}_{3}\right)_{3}, \mathrm{pH} 2$, and (5) with $8.7 \mathrm{~nm}$ of $\mathrm{Cu}$-BTA formed in $\left(\mathrm{NH}_{4}\right)_{2} \mathrm{~S}_{2} \mathrm{O}_{8}, \mathrm{pH} 2$. 
Corrosion protection of $\mathrm{Cu}$-BTA films in environments without $1 \mathrm{H}-\mathrm{BTA}$ reservoir.Accelerated corrosion tests. - $\mathrm{T} / \mathrm{H}$ tests show that $\mathrm{Cu}$-BTA, produced in any of the reported ways, offers signiflciant protection against $\mathrm{Cu}$ oxidation. After two weeks at $80^{\circ} \mathrm{C} / 80 \% \mathrm{RH}$, the as-deposited $\mathrm{Cu}$ film shows significant surface oxidation, with oxide thickness reaching values of $35-42 \mathrm{~nm}$, as measured by ellipsometry, and with the surface changing color to purple and blue. Copper, with a $\mathrm{Cu}$-BTA film, is not totally inert. However, oxidation is slower, corrosion is more uniform, and the surface stays closer to its natural color. The measured oxide thickness is about $19 \mathrm{~nm}$ on the sample prepared in $\mathrm{Fe}\left(\mathrm{NO}_{3}\right)_{3}$ and only about $10 \mathrm{~nm}$ on samples prepared in pH 7 on an oxidized surface. If one accepts the kinetic parameters for $\mathrm{Cu}$ oxidation reported by Sharma et al. (25), T/H data can be used to project the length of the useful life of $\mathrm{Cu}$ under "normal" conditions, such as $30^{\circ} \mathrm{C}$ and $40 \% \mathrm{RH}$. Using $0.6 \mathrm{eV}$ for the activation energy and calculating the effects of water concentration on $\mathrm{Cu}$ oxidation, Sharma and co-workers derived an acceleration factor for $\mathrm{Cu}$ on $\mathrm{T} / \mathrm{H}$ tests to be 154. Assuming that the mechanism of $\mathrm{Cu}$ oxidation stays the same throughout the $\mathrm{T} / \mathrm{H}$ range of interest, an acceptable failure rate after two weeks at $80^{\circ} \mathrm{C}$ and $80 \% \mathrm{RH}$ would mean an acceptable survival for close to seven years at $30^{\circ}$ and $40 \% \mathrm{RH}$.

$\mathrm{Cu} / \mathrm{Cu}$-BTA dissolution in water.-The results of Fig. 1 were obtained in electrolytes which are quite different in their aggressiveness toward $\mathrm{Cu}$. One could speculate that the observed variation in the corrosion rate nearly reflects that factor, irrespective of the possible differences in the $\mathrm{Cu}$-BTA films. The evaluation of the corrosion rate on samples removed from the solutions with $1 H$-BTA, rinsed and dried, and then exposed to water (without added $1 \mathrm{H}-$ BTA) gives a more meaningful comparison of the corrosion resistance offered by different $\mathrm{Cu}-$ BTA films. Results are illustrated in Fig. 9. The corrosion rate decreases from the samples with the $\mathrm{Cu}$-BTA film formed in $\mathrm{pH} 2$ to the samples with the film formed in $\mathrm{pH} 7$ on an oxidized surface. In all cases the samples covered with some $\mathrm{Cu}$-BTA film show higher corrosion resistance than the untreated $\mathrm{Cu}$. Similarly as observed in the solutions containing $1 \mathrm{H}$-BTA, this decrease in the corrosion rate is accompanied by an increase of the corrosion potential. Thus, on a relative scale, the anodic reaction (copper dissolution) is hindered more than the cathodic reaction (oxygen reduction). In aerated water the reduction of oxygen is the only reaction to cause $\mathrm{Cu}$ corrosion. The results show that the factor by which this reaction is suppressed varies from $56 \times$ (on films from neutral electrolytes) to only $3.5 \times$ (for films from acidic solutions). Thus, in spite of a tendency to form thicker films at low $\mathrm{pH}$, the resulting $\mathrm{Cu}$-BTA is more permeable to oxygen and ultimately not as protective as the films formed at neutral $\mathrm{pH}$. The best corrosion protection is offered by the thin film formed on the oxidized $\mathrm{Cu}$ surface, which has shown the slowest growth kinetics and the highest degree of polymerization of the Cu-BTA structure.

\section{Conclusions}

$\mathrm{Cu}$-BTA films offer significant protection against $\mathrm{Cu}$ corrosion in a variety of aggressive electrolytes containing $1 H$-BTA. The films are also effective in environments without a $1 H$-BTA reservoir, e.g., against water and high humidity at elevated temperatures.

The film growth kinetics are limited by ionic movements through the film, which acts as a barrier. Depending on preparation conditions, logarithmic, parabolic, and linear growth laws are observed. 
The growth kinetics are a reflection of the $\mathrm{Cu}$-BTA film structure. The slowest growing films form the thinnest and the most polymerized network of $\mathrm{Cu}$-BTA molecules.

The protectiveness of these films is proportional to the degree of polymerization. The buildup of a polymerized network of BTA-Cu chains is most strongly favored on an oxidized $\mathrm{Cu}$ surface, in solutions in which the $\mathrm{Cu}$ oxides are stable, and $\mathrm{Cu}$ dissolution is slow.

The thermal stability of $\mathrm{Cu}$-BTA varies with film preparation in a reverse fashion from the order observed for corrosion protection. The most protective film starts to desorb from the surface at $199^{\circ} \mathrm{C}$. This may be due to thermal instability of the underlying $\mathrm{Cu}$-oxide. The greatest thermal stability is measured on films formed in $\mathrm{pH} 2$ solutions. These films, however, change with time, most likely due to oxidation at the $\mathrm{Cu} / \mathrm{Cu}$-BTA interface.

\section{Acknowledgment} to this work.

Authors are thankful to S. L. Cohen. R. Thomas, C. Jahnes, C-K. Hu, and D. Pearson for their contributions

Manuscript submitted Dec. 7, 1990; revised manuscript received Feb. 14, 1991. This was Paper 195 presented at the Seattle, WA, Meeting of the Society, Oct. 14-19, 1990.

IBM Research Division, T.J. Watson Research Center, assisted in meeting the publication costs of this article.

\section{REFERENCES}

1. M. Pourbaix, "Atlas of Electrochemical Equilibria in Aqueous Solutions," Pergamon Press, New York (1966).

2. Proctor and Gamble, Ltd., Brit. Pat. 652,339 (Dec.1947).

3. R. Walker, J. Chem. Ed., 57, 789 (1980).

4. S. L. Cohen, V. Brusic, F. B. Kaufman, G. S. Frankel, Sh. Motakef, and B. M. Rush, J. Vac. Sci. Technol. A, 8, 2417 (1990).

5. V. Brusic, S. L. Cohen, F. B: Kaufman, G. S. Frankel, and B. M. Rush, Abstract No. 22-06-03-G, presented at 40th ISE Meeting, Kyoto, Japan, September 17-22, 1989.

6. P. G. Fox, G. Lewis, and P. J. Boden, Corros. Sci., 19, 457 (1979).

7. G. W. Poling, ibid., 10, 359 (1990).

8. D. Chadwick and T. Hashemi, ibid., 18, 39 (1978).

9. G. Lewis, ibid., 22, 579 (1982).

10. C. McCrory and J. M. Rosamilia, J. Electroanal. Chem.,136, 105 (1982).

11. H. G. Thompkins and S. P. Sharma, Surf. Inter. Anal, 4, 262 (1982).

12. M. Ito and M. Takahashi, Surf. Sci., 158, 609 (1985).

13. F. Mansfeld, T. Smith and E. P. Pery, Corrosion, 27, 289(1971).

14. B-Sh. Fang, C. G. Olson, and D. W. Lynch, Surf. Sci.,176, 476 (1986).

15. J.-O Nilsson, C. Tornkvist, and B. Liedberg, Appl. Surf. Sci., 37, 306 (1989).

16. M. Oertel, P. Klusener, M. Kemken, A. Benninghoven, H. J. Rother, and R. Holm, Appl, Surf. Sci., 37, 135 (1989).

17. D. Thierry and C. Leygraf, This Journal, 133, 2236 (1986).

18. M. A. Frisch, in "Advances in Mass Spectrometry," Vol. 8A, A. Quayle, Editor, p. 391, Heyden, London (1980).

19. M. A. Frisch and W. Reuter, J. Vac. Sci. Technol, 16, 1020 (1979).

20. D. Briggs and M. J. Hearn, Vacuum, 36, 1005 (1986).

21. D. Briggs, A. Brown, and J. C. Vickerman, "Handbook of Static Secondary Ion Mass Spectrometry," John Wiley \& Sons, New York (1989).

22. B. N. Eldridge, Rev. Sci. lustrum., 60,3160 (1989).

23. V. Brusic, M. Russak, R. Schad, G. Frankel, A. Selius, D. Dimilia, and D. Edmonson, This Journal, 136, 42 (1989).

24. J. B. Cotton, Proceedings of the 2nd International Congress on Metallic Corrosion, NACE, New York (1963).

25. S. P. Sharma, J. H. Thomas III, and F. E. Bader, This Journal, 125, 2002, 2005 (1978). 